\title{
Business Processes as Social Entities - A Use Case Driven Approach
}

\author{
Dirk Werth \\ German Research Center for Artificial Intelligence (DFKI) \\ dirk.werth@dfki.de \\ Christina Di Valentin \\ German Research Center for Artificial Intelligence (DFKI) \\ Christina.diValentin@iwi.dfki.de
}

\begin{abstract}
Social media represents one of the most rapidly growing trends in information technology. Up to now, however, this trend has been mainly driven by private users, although in organizational context social media technologies would provide a multiplicity of benefits. This paper shows based on a state of the art analysis - application potentials of social media in the field of business process management (BPM). The focus lies on the interplay between the subjects and objects of BPM and social media. The goal is to turn business processes into social entities with the capability to communicate and to take on identity. Based on a holistic idea finding process, several potential use cases are arranged within the phases of the BPM cycle. The results show that unexploited potentials exist particularly in the phases of "Business Process Design" and "Business Process Controlling".
\end{abstract}

Keywords: Social Business Process Management, Social Networking, Social Media. 


\section{Introduction}

\section{Motivation and Contribution of the Research}

Social software is one of the most rapidly growing trends in information technology. This can be attributed to the fact, that "social software" typifies a new paradigm which supports both the interaction of human beings and the production of artifacts (Schmidt and Nurcan, 2008). Up to now private consumers outweigh the scope of application compared to the use of social media in organizational context, although an efficient adoption of social software with enterprise software would provide a multitude of communication and collaboration possibilities. The power of social interactions is nothing new. In the early 70 s and 80 s, concepts of social interactions like Granovetter's weak ties already discussed the benefits of social interactions without knowing the feasibilities to realize them by the use of software systems (Granovetter, 1973, 1983).

Current developments demonstrate that the use of social media for commercial purposes increases. A recently carried out study by Forrester has shown that "Social Business Process Management (BPM)" represents one of the most meaningful trends in the field of BPM (Forrester, 2008). Enterprises already applying social media in their business processes declared a positive contribution to their success by improvements of productivity and customer relationships as well as increasing revenues (Lattemann, Stieglitz and Kupke, 2009; Patten and Keane, 2010). Additionally to these benefits, the use of social media tools in most cases has also proven to be a cost saving method (Cooke and Buckley, 2008). Many companies already integrate their customers into product development (e.g. by the use of blogs) to capture innovative ideas which can be yielded in product design and enhancement of products (Erol et al., 2010).
The added value of social media tools mainly relies on an effective and efficient coordination, communication and cooperation between business and customers. Nevertheless, the same positive effect may not only be realized across company boarders but also within a company as it offers employees better integration possibilities as well as new alternatives for a flexible design of business processes (Erol et al., 2010). The profitable application of social media (both synchronous and asynchronous communication and collaboration tools) offers much potential for an effective and efficient coordination, communication and cooperation within BPM. Synchronous (e.g. instant communication) as well as asynchronous (e.g. wikis, blogs) communication tools play a significant role particularly in the design and controlling phase of business processes. In the modeling phase, social media tools enrich business processes by enabling employees to actively contribute their knowledge. Hence, it can be ensured that employees responsible for carrying out or managing certain business processes have the chance to offer their knowledge anytime within all phases of the BPM cycle (consisting of the phases strategy, design, implementation and controlling), which goes along with a higher degree of profitability (Emrich, Ganz, Werth and Loos, 2010; Erol et al., 2010). One approach is the inclusion of social media functionality in other enterprise software, e.g. by Salesforce Chatter. The potentials that come along with the communication and collaboration possibilities provide enterprises with so far unrealized new functionalities and application scenarios.

Social media may not only be used by employees when carrying out operational tasks but also in terms of BPM (Erol et al., 2010). This article investigates this potential, by turning business processes into social entities. The ordinary and fixed construction plan within the modeling and execution phase of business processes is not in the 
focus any longer. The consideration of dynamic aspects in BPM has already been a focus in literature and practice. Burkhart et al. developed a concept about managing email based business processes and tailor them to the needs of SME's. The developed prototype supports SME's to manage the high flexibility as well as personal and company individual requirements of e-mail communication to make e-mail based workflows easier, faster and more structured (Burkhart, Krumeich, Werth and Loos 2011).

The outline of the manuscript is as follows: The next section describes the methodology of the applied research work followed by an introduction of the foundations and basic tools of social media as well as a description of the BPM cycle. Therefore, a literature analysis has been carried out to identify which social media tools are applied within each phase of the BPM cycle. The Chapter "Business Processes as Social Entities" describes the subjects and objects in social networks which form the basis for the use cases to be presented. These use cases demonstrate the added value for enterprises through the use of social media, particularly in form of social networks. The main goal of this research work is to push forward innovative concepts and to form a basis to develop more IS artifacts in the context of social media enhanced business processes. The paper closes with a conclusion and an outlook on future research.

\section{Methodology}

The research work follows a design-oriented methodology (Hevner, March, Park and Ram, 2004; March and Storey, 2008). The subject matter of design science is the artificial creation of innovative artifacts (Hevner et al., 2004). According to Hevner's (2004) guidelines for design-oriented research, these artifacts can be classified into constructs, models, methods and instantiations. A basic principle of information systems research is the arbitrary influence of business and IT on one another (Scheer, Kruppke, Jost and Kindermann, 2007). Therefore, new IT trends such as social media have an impact on existing artifacts and enable the design of new artifacts.

In this paper, a collection of ideas for new artifacts is created and explained considering Hevner's guideline "Design as a search process", according to which different alternatives for artifacts or artifact designs are being analyzed in their problem environment (Hevner et al. 2004). In order to enhance the rigor of the use case approach, the recommendations of case studies by Dubé and Paré (2003) have also been taken into consideration (particularly in terms of design issues). The use case approach is specifically suitable for social media scenarios, as different social media principles can be applied and analyzed regarding their applicability in a certain problem context.

Hence, this paper serves as a starting point for constructing new IS artifacts based on social media principles. In order to create first constructs based on these ideas, a specific vocabulary and terminology is being developed. In order to proof its relevance for IS research these constructs will be evaluated against rigorous, existing approaches in literature and user requirements (e.g. in terms of user questionnaires, focus groups, etc.). After dismissing the irrelevant artifacts, the remaining constructs will be transferred into models, method and tools in future work relying on accepted IS research methods. The research questions we follow are:

- How can BPM benefit from social media, particularly social networks?

- How can business processes be transformed from object state into subjects? (business processes with social entity)

- What are the characteristic properties of "social business processes"? 
Therefore, we assess the ability of business processes as an actor within social media. In doing so, we collect information about the ability of the different kinds of social media regarding the support they offer when carrying out activities in terms of BPM (e.g. modeling or controlling of business processes).

\section{Foundations}

\section{Social Media in Organizational Context}

This section gives an overview of several social media applications, which are going to be picked up in the use cases to be derived. Social media tools (alternatively web 2.0) turn users into designers (O'Reilly, 2005) by facilitating them to provide selfproduced contents to other users in the web (Kollmann and Häsel, 2007). This is accompanied by an effective networking of users and a large number of design and communication options. these aspects play a significant role, particularly in terms of BPM, as they come along with a higher degree of efficiency (Wirtz and Ullrich, 2008). By this means, the importance of the Internet and its role as interaction and cooperation platform is continuously growing (Beck, 2007). Closely related to social media is the concept of "enterprise 2.0" which is of great importance in the outline of this manuscript. The term "enterprise 2.0" mainly emerged with the advent of discussing the benefits of social media tools in organizational context (McAfee, 2006).

The growing importance of social software usage has already been addressed in 2008. Forrester conducted a study addressing the frequency of social software usage in North American and European enterprises to find out whether companies have already implemented social software or if they are currently in an installation or piloting phase (Forrester, 2008). The results have shown that by this time already $28 \%$ of the interviewed companies (total number of surveyed companies was 1000) already used wikis, followed by blogs (27\%), feeds and social networks (22\%). Merely microblogs (11\%) and mash-ups (9\%) represented applications with a small proportion compared to the other social media tools. A more recently carried out study in 2011 revealed that by the year 2016 enterprises will increase their expenses on social collaboration software with an annual growth rate of $61 \%$ (Forrester, 2013).

Table 1 lists the most common social media tools that play an important role for the use cases presented in this manuscript.

The choice of the technologies has been derived on the basis of a holistic literature analysis (Alby, 2008; Kollmann and Häsel, 2007; Ras, Rech, and Weber, 2009; Voss, 2007; Weber and Rech, 2009): 


\begin{tabular}{|c|c|}
\hline Annotations & $\begin{array}{l}\text { Annotations comprise activities of content creation and } \\
\text { commenting on content. Hence, annotations support } \\
\text { collaborative content creation, which comes along with an } \\
\text { improvement of its quality. In organizational context } \\
\text { annotations can be used to find, understand and evaluate } \\
\text { specific content provided by other employees. }\end{array}$ \\
\hline Blogs & $\begin{array}{l}\text { Blogs are regularly actualized web-based diaries } \\
\text { containing contributions in a chronological or thematically } \\
\text { order. In most cases, the created content is freely } \\
\text { accessible by users in the web. Users who keep this form } \\
\text { of diary are also called "blogger". Blogs enable to address } \\
\text { a large number of users in the web. Hence, the blogger's } \\
\text { social presence is on a high level (Kaplan \& Haenlein, } \\
2010 \text { ). Another aspect about blogs is that in most cases, } \\
\text { readers of a blog have the opportunity to write comments } \\
\text { and to discuss about the topics presented in the blog. }\end{array}$ \\
\hline Folksonomy & $\begin{array}{l}\text { Folksonomy is the collaborative creation and management } \\
\text { of tags with the aim to annotate and categorize content. } \\
\text { Instead of experts, it is the user that is enabled to index } \\
\text { different objects. Hence, a collaborative generation and } \\
\text { finding of a common vocabulary is supported. Folksonomy } \\
\text { should not be mixed up with the term "collaborative } \\
\text { tagging" which enables several persons to add tags to any } \\
\text { specific item. An example for collaborative tagging is } \\
\text { Delicious. The benefit that comes along with the concept } \\
\text { of folksonomies is that users can tag items. Hence, these } \\
\text { tags can be found easily (Anderson, 2012). }\end{array}$ \\
\hline News Aggregators & $\begin{array}{l}\text { News aggregators are tools for an aggregated retrieval of } \\
\text { information from the web (e.g. Google News). News } \\
\text { aggregators comprise a concept of syndication which } \\
\text { offers users an automated information supply from the web } \\
\text { without the need for accessing certain websites. }\end{array}$ \\
\hline Open Interfaces & $\begin{array}{l}\text { Open interfaces facilitate the integration of a service in } \\
\text { another application, without the need to activate the } \\
\text { service manually. Thus, data and functions of new } \\
\text { developed applications can be activated via a simple API. }\end{array}$ \\
\hline
\end{tabular}




\begin{tabular}{|c|c|}
\hline Podcasts & $\begin{array}{l}\text { Podcasts comprise the generation and dispersion of media } \\
\text { data (mainly audio files) via the web. The term "podcast" } \\
\text { emerged from the terms "iPod" and "Broadcasting". One } \\
\text { podcast consists of several media episodes which can be } \\
\text { subscribed by users, e.g. via a news aggregator. Users } \\
\text { can listen to podcasts regardless of aspects of time. }\end{array}$ \\
\hline $\begin{array}{l}\text { Social Tagging/ } \\
\text { Bookmarking }\end{array}$ & $\begin{array}{l}\text { Social Tagging / Bookmarking represent services for } \\
\text { administration and exchange of references and websites } \\
\text { (e.g. Delicious). Within Social Tagging buzz phrases are } \\
\text { assigned through collaborative (shared) indexing of } \\
\text { information objects (e.g. pictures, links, videos, etc.). } \\
\text { Social Bookmarks can be created by several users and be } \\
\text { centrally memorized on a server in the Internet. Hence, } \\
\text { users are enabled to access and change the bookmarks. } \\
\text { In most cases, users access this service via a web } \\
\text { browser. }\end{array}$ \\
\hline Social Networks & $\begin{array}{l}\text { Social networks (e.g. Facebook, Linkedln) represent } \\
\text { communication platforms supporting interaction and } \\
\text { collaboration between individuals through networking of } \\
\text { friends, commenting on contributions and private } \\
\text { communication. One characteristic about social networks } \\
\text { is that a user's self-presentation as well as social presence } \\
\text { are on a high level (Kaplan and Haenlein, 2010). }\end{array}$ \\
\hline Wikis & $\begin{array}{l}\text { Wikis comprise a collection of websites containing a } \\
\text { collective generation of contents. A significant benefit } \\
\text { about wikis is the low effort in editing, adding or preparing } \\
\text { of contributions. Hence, the user's self-disclosure as well } \\
\text { as their social presence is on a low level compared to e.g. } \\
\text { social networking sites (Kaplan and Haenlein, 2010). }\end{array}$ \\
\hline
\end{tabular}




\section{Business Process Management (BPM)-Lifecycle}

In order to compete, it becomes increasingly important for enterprises to be able to continuously adapt the current business processes to changing customer needs (Malone, Weill, Lai, Urso, and Herman, 2007). This goes along with a higher degree of efficiency which enables companies to realize so far unexploited potentials. Therefore, it is important for companies to define controllable objectives. When defining these objectives (effectiveness) companies must also pay attention to their transformation in practice (efficiency). Many problems about effectiveness and efficiency can be ascribed to the iniquitous management and control of business processes.

BPM helps to significantly reduce these problems of efficiency and effectiveness (Schmelzer and Sesselmann, 2008) by representing methodologies and concepts for management, organization and controlling of business processes, which enables enterprises a precise supervision and analysis of their business processes (Weske, 2007). Thus, the concept of business processes, which is required to reach strategic and operative goals, aims at fulfilling the needs of customers and further interest groups (employees, investors, etc.). Literature about BPM differentiates between "technology based BPM" and "business BPM" (Scheer et al., 2007). Technology based BPM represents the implementation and automation of business processes, whereas the latter is seen as a management concept (Schmelzer and Sesselmann, 2008).

In literature, the management of business processes is often presented in form of several phases. In this manuscript we take the BPM cycle consisting of 4 phases according to (Scheer et al., 2007) as a basis:

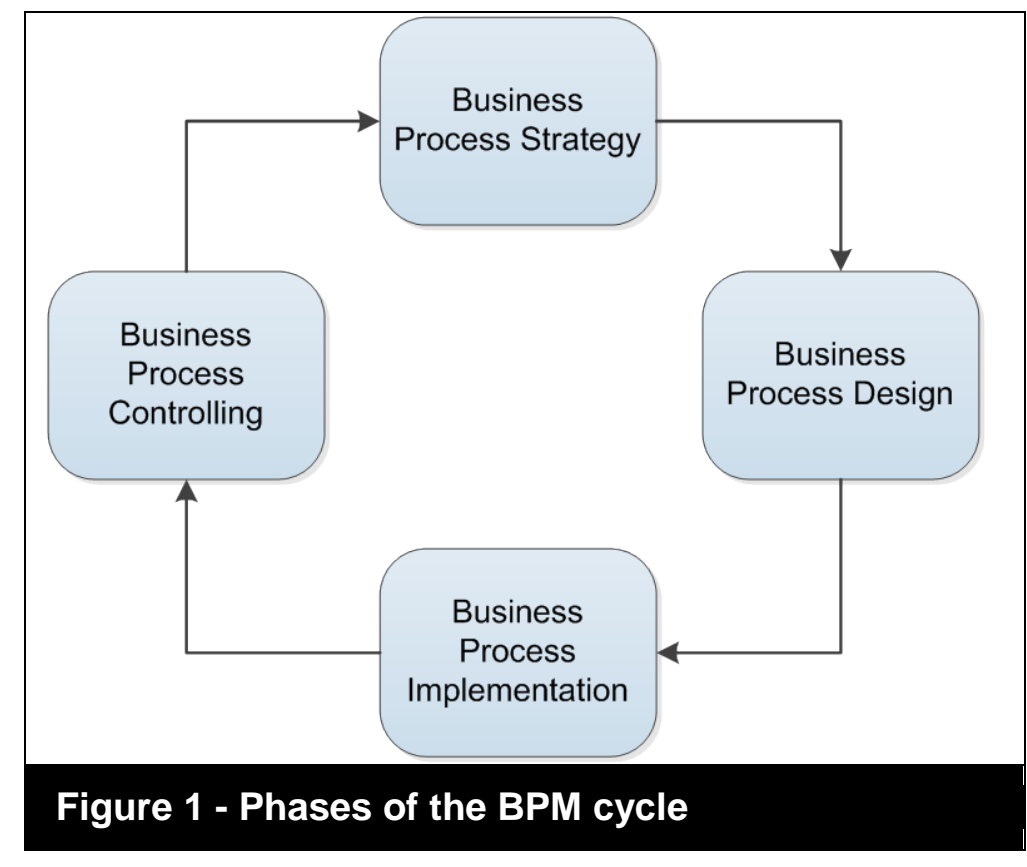

The phase "Business Process Strategy" represents the creative part within the BPM cycle. It forms the basis for adapting business processes to a company's strategy. This phase is of long-term importance, because dependent on both, a company's underlying business model as well as the surrounding market environment, companies are often forced to adapt their strategy to changing influencing factors 
Business Processes as Social Entities - A Use Case Driven Approach / Werth et al.

(Back, Gronau, and Tochtermann, 2008; Di Valentin, Emrich, Werth and Loos, 2012; Komus, 2006; vom Brocke and Rosemann, 2010; Weber and Rech, 2009). "Business Process Design" and "Business Process Controlling" are focused on the documentation and execution of business processes (Kaplan, Robert \& Norton, David, 1992; Komus, 2006; Lai \& Turban, 2008; Wagner \& Klückmann, 2006). The phase "Business Process Implementation" plays an important role, particularly in terms of the transition of two lifecycle phases (Komus and Wauch, 2008; Scheer et al., 2007). Within this phase, the designed business processes are implemented in the underlying enterprise software. "Business Process Controlling" focuses on the planning of critical success factors as well as the coordination of strategic goals of the business process (Schmelzer and Sesselmann, 2008). Hence, the main goal of this phase is a qualitative and quantitative analysis of accomplished business processes based on aggregated key measures. These key measures can be used afterwards in the phase of "Business Process Strategy" to carry out analyses about the strategy which is currently implemented.
So far, literature has focused on several aspects regarding the potentials of social media in the context of BPM. Based on a comprising literature analysis, the social media tools presented in the previous section have been assigned to the different phases of the BPM cycle. Further information about the classification method can be also found in (Houy, Fettke and Loos, 2010).

The potentials of the analyzed social media tools have been classified in a reference framework (see Table 2). The analysis has focused on the frequency with which classifications of social media applications are cited in literature according to the closed loop of BPM. Social media tools containing much potential within a certain phase of the BPM cycle are identified with a "+". This means that these applications have already been mentioned in literature or they have already been used in practice within the certain phases of the BPM cycle. Applications that have not been discussed in literature in relation to BPM so far are marked with a "-". Social media tools that are assigned a "O" have not been discussed in literature, however several application potentials in practical context have been demonstrated.

\begin{tabular}{|l|c|c|c|c|}
\hline Table 2 - Potentials of Social Media in BPM & Implementation & Controlling \\
\hline $\begin{array}{l}\text { Social Media } \\
\text { Applications }\end{array}$ & Strategy & Design & - & - \\
\hline Annotations & - & + & + & + \\
\hline Blogs & - & - & O & + \\
\hline Folksonomy & O & + & - & - \\
\hline Instant Communication & - & + & & + \\
\hline News Aggregators & + & O & O & + \\
\hline Podcasting & - & - & + & + \\
\hline Open Interfaces & - & + & - & - \\
\hline Social Tagging & - & + & + & + \\
\hline Social Networks & O & + & + & - \\
\hline Wikis & + & + & & + \\
\hline
\end{tabular}


The table above has been extended on the basis of (Houy et al., 2010; Werth, Di Valentin, Burkhart and Loos, 2012). It shows that in practice much potential of social media has not been exploited so far within BPM. Particularly social networks (highlighted row) are characterized by a large potential which also plays a significant role in this manuscript. Particularly global acting enterprises may benefit by the use of social networks as they could support e.g. intra-group coordination of several areas of responsibility. Many employees already apply tools of social networks (e.g. Facebook or YouTube) not only in private but also in professional context (Bicknell, 2009). However, the proportionality is still unbalanced (Forrester, 2013) and the potentials so far are not sufficiently exploited.

Within the phase "Business Process Strategy" social media tools enable the exchange of ideas and thus a collaborative constitution of strategies and visions. Wikis are often associated in literature with the phase of "Business Process Design", (Komus, 2006; Lai and Turban, 2008) in which they can for example support a collaborative modeling of business processes. Social networks and Instant Communication tools so far support finding the right contact persons within a specific process community. Within the phase of "Business Process Implementation" social networks support finding required process know-how, whereas blogs, wikis and podcasts support offering training material for the implementation of certain process steps. The most mentioned social media tools in the phase of "Business Process Controlling" are blogs and social networks as they enable a collaborative monitoring and evaluation of business processes. The following chapter describes the subjects and objects in social networks and how business process can turn into social entities.

\section{Business Processes as Social Entities}

\section{Subjects and Objects in Social Networks}

Social software supports social interactions and social production. Thereby, social interactions encompass the interactions of non-predetermined individuals, whereas social production comprises the creation of artifacts. These artifacts can be either content or context information concerning artifacts or physical objects (Schmidt and Nurcan, 2008). Wikipedia is an example for social production: input from independent contributors is combined without predetermining the way (Schmidt and Nurcan, 2008). Thus, social software supports individuals to produce digital goods in form of knowledge and content by combining their contribution. Thereby, the individuals responsible for the content creation do not have to know each other. In this manuscript, the interplay between subjects and objects within BPM is the focus. The goal is to transform business processes from objects into subjects by giving them the characteristics of subjects. Therefore, we first have to be clear about the distinction of subjects and objects. A subject represents an acting person who treats a specific object. In terms of BPM this means, that a subject is a person acting with an object represented by the business process.

In the following, the activities of subjects concerning their interactions within social media are explained by means of Kietzmann's (2011) "honeycomb of social media":

- Sharing: The extent to which users exchange, distribute and receive content.

- Presence: The extent to which users know if other users are available.

- Relationships: Describe the extent to which users relate to each other within a social network. 
Business Processes as Social Entities - A Use Case Driven Approach / Werth et al.

- Identity: The extent to which users reveal themselves.

- Reputation: The extent to which users know the social standing of others and content.

- Groups: The extent to which users are ordered or form communities.

- Conversations: The extent to which users communicate with each other.

The social media tools presented in Table 1 provide a number of benefits in BPM context. Particularly knowledge intensive processes (tasks that do not occur on a regular basis) may profit from the use of these tools as they facilitate communication and collaboration as well as a logging of business activities that have been carried out. Hence, a history of a company's working activities can be provided which e.g. can be helpful in suddenly occurring exceptional cases. Further, benefits are an improvement of the employee's selfidentification as any employee willing to contribute to activities within BPM is allowed to do so (Erol et al., 2010). Hence, employees contributing their knowledge identify themselves as competent (otherwise this content or knowledge would not have been provided). The content provided by users can also be openly modified by other employees by offering them the possibility to contribute their knowledge ("collective intelligence", "social production"). This comes along with a higher degree of transparency as all work results can be made openly available for all stakeholders within the enterprise (preconditioned that access to specific contents can be regulated centrally).

To ensure the aspect of "Sharing" in organizational context, social graphs and content management systems are required to generate information about the employees' behavior of interactions (Kietzmann, Hermkens, McCarthy, \& Silvestre, 2011). To describe the relationship of users amongst each other in terms of the aspect "Relationships", the structural and flow properties within a network of relationships have to be managed (Kietzmann et al., 2011). Further, legal aspects (data privacy), monitoring of strength, passion (reputation), membership rules (groups), conversation velocity as well as risks of starting and joining (Kietzmann et al., 2011)are aspects that companies have to take into consideration.

In practice, an integration of social media with objects has already been carried out. An example for transforming an object into a social entity is "Toyota Friend", a strategic alliance of Toyota with Salesforce.com which has been launched in 2011. It represents a social network for customers of Toyota and their cars (Muller, 2011). Drivers are provided real-time information which can be helpful for users in their current context. For instance information about the battery level and thus about nearby charging stations can be provided. Another example for this information exchange between the user and an object are notifications in form of an alert by the car concerning the upcoming appointment for inspection. Hence, the car provides its owners information anytime that matches to the user's current situation (Muller, 2011). By this means, the car becomes a social entity with the ability to communicate with the user. The goal of the research work in this manuscript is to transform business processes into social entities by integrating them with social networks. Hence, employees shall be enabled to communicate with business processes.

\section{Business Processes as Subjects of Social Networks}

This section describes how the activities of subjects concerning their interactions with social media according to Kietzmann's (2011) honeycomb can be adopted to business processes when they act as subjects in a social network. Thereby, the potentials and activities within each component of the honeycomb are identified in terms of BPM. 
- Sharing: Business processes acting as social entity have the possibility to exchange and distribute information. When acting as a subject, business processes are also enabled to receive knowledge from other subjects (employees or business processes). By this means, business processes have the possibility to continuously enrich their knowledge.

- Presence: Generally speaking, this aspect represents the extent to which users know if other users are available in a social network. Business processes that act as social entity have the ability to identify which employee is available in which business process. Hence, if an exceptional case occurs, business processes have the ability to contact the right person available. In the long run, this results in time savings as problems can be solved quickly this way.

- Relationships: Describe the extent to which users and business processes relate to each other in a social network. Thereby, a business process can connect to other business processes as well as to an organization's employees.

- Identity: When business processes act as subjects within a social network, not only employees but also business processes have the possibility to reveal themselves. In doing so, business processes can e.g. indicate specific characteristics / information about themselves.

- Reputation: This aspect describes the extent to which users know the social standing of other users and the content of a social network. A requirement for indicating and getting informed about the social standing of other participants within a social network is the aforementioned characteristic of "Identity". Hence, employees and business processes are enabled to contact the right persons in exceptional cases. However, to ensure privacy, the visibility of profile information should be limited to specific stakeholders, also in order to avoid information overload.

- Groups: Groups describe the way users and business processes form communities. Business processes that act as subject within a social network are able to form groups with employees in which knowledge can be shared.

- Conversations: The extent to which users and business processes communicate with each other. Business processes can act as a communication partner within a social network. Hence, process-relevant information can be shared in real-time with the stakeholders of a specific business process (see also the example of "Toyota Friend").

The following section describes potential use cases for an efficient use of social network applications in organizational context in which business processes are described as subjects of social networks.

\section{Use Cases for a Social Process Network}

Within this chapter, several potentials for social media applications in BPM are depicted. The use cases are based on the phases of the BPM cycle of the chapter "Foundations". Thereby, each use case is assigned to one or more phases of the BPM cycle. In addition to an explanation of the concrete use case, several benefits and disadvantages on the users' point of view are going to be explained. Furthermore, required technologies and efforts for the implementation of the use cases are identified. We chose the method of deriving use cases because it allows analyzing different social media disciplines regarding their applicability in a specific context.

\section{Social Optimization and Development of Business Process Steps}

The use case presented in this section plays a significant role in the phases of "Business Process Design" and "Business Process Controlling". This scenario aims at 
Business Processes as Social Entities - A Use Case Driven Approach / Werth et al.

continuously optimizing and developing business processes by the use of social tagging. Employees are enabled to carry out collaborative and shared indexing of information objects in the business process. As soon as an application is active, texts and pictures (e.g. from web, word or excel) can be marked with a "magic paint brush" and be added to a specific process step. This scenario could be easily integrated in the context menu of system software. Hence, the annotation of business processes or a single process step to any document, file or additional information could be enabled.
Employees involved in interfaced process steps can be provided information in a graphically represented or structurally prepared manner. By this means, each employee can gain insight in required and context sensitive information which enables employees to consequently add tags to a specific process step. As employees are offered to continuously enrich certain process steps with their knowledge, this scenario offers much potential, particularly in the phase of "Business Process Design".

\begin{tabular}{|c|c|}
\hline $\begin{array}{l}\text { Benefits from the } \\
\text { employees' point of } \\
\text { view }\end{array}$ & $\begin{array}{l}\text { - As inferences can be gained about the required } \\
\text { information within a certain process step, the } \\
\text { quality of process models and process support can } \\
\text { be increased by annotating business processes } \\
\text { with additional information. } \\
\text { - Employees can be provided an overview of } \\
\text { information regarding a specific process step that } \\
\text { has been released by other users. } \\
\text { - During operative process execution, relevant } \\
\text { information can be quickly distributed. }\end{array}$ \\
\hline $\begin{array}{l}\text { Disadvantages from the } \\
\text { employees' point of } \\
\text { view }\end{array}$ & $\begin{array}{l}\text { - A realization of this use case comes along with the } \\
\text { requirement of a control mechanism to } \\
\text { continuously supervise tagged information. } \\
\text { - The distribution of incorrect information has to be } \\
\text { avoided. }\end{array}$ \\
\hline $\begin{array}{l}\text { Required technologies } \\
\text { and development } \\
\text { expenses }\end{array}$ & $\begin{array}{l}\text { - Software that is capable to offer an individual } \\
\text { overview of each process step as well as an } \\
\text { overview of recent tags. } \\
\text { - The application should enable annotations in } \\
\text { almost each application system and web browser. } \\
\text { - The application must be easy to integrate with } \\
\text { enterprise software. }\end{array}$ \\
\hline $\begin{array}{l}\text { Controllability/Safety of } \\
\text { the used technologies }\end{array}$ & $\begin{array}{l}\text { - Messaging services must be able to inform the } \\
\text { process responsible about tagged information to } \\
\text { ensure that no incorrect information or other } \\
\text { inappropriate contents are annotated. }\end{array}$ \\
\hline
\end{tabular}




\section{Collaborative Specification of Business Objectives and Key Measures}

The use case "Collaborative Specification of Business Objectives and Key Measures" can be assigned to the BPM phase "Business Process Strategy" as in this phase, an effective use of information from controlling plays a significant role. This scenario focuses on supporting a company's management level by the use of wikis. Within the collaborative specification of business objectives and key measures, department specific as well as company specific goals including the corresponding key measures are planned to be defined by the responsible head of the department and/ or the CEO.
This is accompanied by a higher degree of transparency. Additionally, employees are enabled to adapt specific objectives and key measures by submitting their own suggestions in the proposed wiki. Hence, affected individuals can be informed via communication media like Twitter or e-mail about the proposed suggestions. Furthermore, employees and supervisors are motivated to vote or comment on the proposed suggestions. Based on the voting and the comments, responsible controllers on strategic level can decide about possible modifications on the current target system or the defined key measures. Hence, it can be ensured that predefined objectives are not measured by inappropriate key measures.

\begin{tabular}{|c|c|}
\hline $\begin{array}{l}\text { Benefits from the } \\
\text { employees' point of view }\end{array}$ & $\begin{array}{l}\text { - Optimized definition of strategic objectives as } \\
\text { suggestions from operative level (bottom-up) can be } \\
\text { gained (instead of top-down, beginning from strategic } \\
\text { level). } \\
\text { - Motivation of employees by offering the possibility to } \\
\text { bring in their individual opinion. } \\
\text { - Transparency about the definition of strategic } \\
\text { objectives in each enterprise level. } \\
\text { - Optimized definition of strategic goals. }\end{array}$ \\
\hline $\begin{array}{l}\text { Disadvantages from the } \\
\text { employees' point of view }\end{array}$ & $\begin{array}{l}\text { - Strategic objectives and key measures represent } \\
\text { sensible data. Hence the system must be moderated } \\
\text { in a topic oriented manner. } \\
\text { - Employees might propose strategic objectives based } \\
\text { on each individual's interests instead of corporate } \\
\text { interests. }\end{array}$ \\
\hline $\begin{array}{l}\text { Required technologies } \\
\text { and development } \\
\text { expenses }\end{array}$ & $\begin{array}{l}\text { This scenario requires clearly arranged wiki software } \\
\text { (first external procurement of the software, then } \\
\text { customizing or in-house development). Employees } \\
\text { could get access to the wiki e.g. via the web browser. } \\
\text { Database software, which is supported by the wiki } \\
\text { software as well as a corresponding database server } \\
\text { are required for the implementation of this use case. }\end{array}$ \\
\hline $\begin{array}{l}\text { Controllability/Safety of } \\
\text { the used technologies }\end{array}$ & $\begin{array}{l}\text { - The required technology can be limited on in-house } \\
\text { platforms and devices. From a conceptual point of } \\
\text { view, security holes can be kept on a low level. }\end{array}$ \\
\hline
\end{tabular}




\section{Table 5 - Characteristics of Use Case 3}

\begin{tabular}{|l|l|l|}
\hline Benefits from the & $\begin{array}{l}\text { Efficient distribution of news by using an established } \\
\text { employees' point of view }\end{array}$ & $\begin{array}{l}\text { push concept (e.g. RSS feed or Twitter) } \\
\text { All relevant information can be aggregated in a } \\
\text { context-sensitive form and provided to the user. } \\
\text { - }\end{array}$ \\
The entity of notifications about modifications can be \\
used as documentation of changes/history of a \\
business process. \\
- In each message the originator who is available for \\
questions and critics can be mentioned.
\end{tabular}




\section{Twitter my Business Process}

This use case can be applied within all phases of the BPM cycle as social networks like Twitter offer employees the possibility to collaborate in several application fields such as design, implementation or controlling of business processes as well as in terms of strategic decisions. Thus, employees can e.g. share information about decisions concerning specific business processes or within the design phase of specific business processes. Software developers could share information and collaborate within the implementation phase of business processes. Hence, employees can learn from other (more experienced) employees and share their knowledge. This use case focuses on push services to distribute information to certain processes or parts of a business process. By subscribing to a business process, employees become its followers. If changes in a subscribed business process occur, employees are informed via push service about these modifications. This function could be offered e.g. as a separate tool or via integration into an existing e-mail client (e.g. MS Outlook or Lotus Notes). Additionally, a distribution of business process changes could also be conducted in form of a short message service (SMS) on mobile device or webbased messaging service. Thereby, the formulation of the messages has to be carried out by the process manager to ensure a distribution of validated information. Modifications directly affecting the process model could be e.g. generated automatically in a process tool (e.g. ARIS).

The following figure gives an overview of the BPM cycle with its assigned use cases:

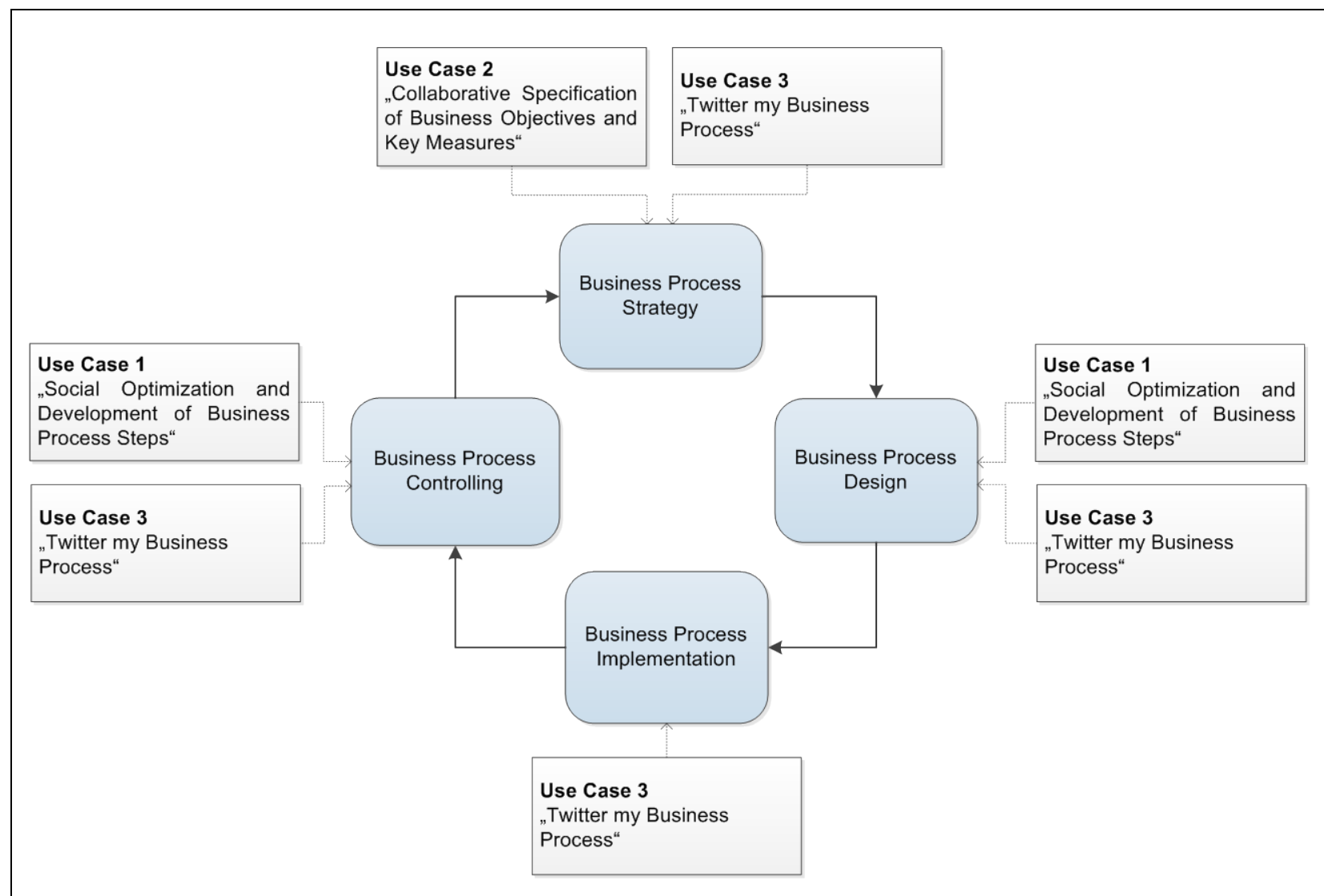

Figure 2 - Phases of the BPM cycle with the derived Use Cases assigned to each Phase 


\section{Conclusions and Outlook}

This manuscript depicted potentials for BPM which are induced by the use of social software. The presented use cases provide insights how social media can be useful for IS artifacts in BPM. In doing so, potential possibilities have been presented which describe how to integrate social media with BPM to make business processes become social entities. First, the phases of the BPM cycle have been demonstrated based on a comprehensive literature review with regard to the use of social media tools. Especially the phases "Business Process Design" and "Business Process Controlling" are characterized by a large amount of so far unexploited potentials. The use cases have shown that it is possible to integrate social media with organizational BPM with little effort. A characteristic aspect of the demonstrated use cases is that users are always in the main focus of attention as social media enables to actively participate in terms of process design. By applying collaborative methods, it is possible to integrate several individuals in the design or optimization of a certain business process. Thus, the user feedback is not only based on the opinion of one individual but also of several employees who are integrated in a certain business process step. Hence, pieces of advice for an efficient process optimization can be put into practice. This would not be possible with classic methods of process design. Future studies should create concepts for those use cases as well as implement and evaluate them according to rigorous design science methods. By and large, this should help to advance BPM as discipline by leveraging social media. Furthermore, the derived concept gives potential to develop more IS artefacts in the context of social media enhanced business processes.

The results depicted in this paper can be used as scope of action for integrating social media with enterprise software. The use cases show in which phase of BPM the largest potential by the use of social media tools can be achieved. By this means, the use cases represent an optimal starting point for the conception of a social BPM solution.

However, the research work also has several limitations. In the context of the presented use cases, we assume that a company's top management does not determine the role of software users which is a usual characteristic in the traditional approach. We realize that the use of social software in organizational context follows a bottom-up approach in which the employee's interactions are coordinated by the collective intelligence of each individual. Hence, aspects about legal issues and reputation play a significant role when transferring the derived use cases into practice (e.g. banning the inputs of employees that provide inappropriate content). 


\section{References}

Alby, T. (2008). Web 2.0 - Konzepte, Anwendungen, Technologien. Munich: Carl Hanser.

Anderson, P. (2012). Web 2.0 and Beyond Principles and Technologies. CRC Press.

Back, A., Gronau, N., and Tochtermann, K. (2008). Web 2.0 in der Unternehmenspraxis. Munich: Oldenbourg.

Beck, A. (2007). "Web 2.0: Konzepte, Technologien, Anwendungen," HMD - Praxis der Wirtschaftsinformatik, 255.

Bicknell, D. (2009). Make Web 2.0 deliver business benefits. Retrieved from http://www.computerweekly.com/Arti cles/2008/02/20/229486/make-web2.0-deliver-business-benefits.htm on June 10, 2013.

Burkhart, T., Krumeich, J., Werth, D., and Loos, P. (2012). "Flexible Support System for Email-based Processes: An Empirical Evaluation," International Journal of E-Business Development (IJED), 3(2), pp. 77-85.

Cooke, M., and Buckley, N. (2008). "Web 2.0, social networks and the future of market research," International Journal of Market Research, 50(2), pp.267-292.

Di Valentin, C., Emrich, A., Werth, D., and Loos, P. (2012). "Conceiving Adaptability for Business Models - A Literature-based Approach," International Conference on Information Resources Management (Conf-IRM), Vienna.

Dubé, L. and Paré, G. (2003). "Rigor in Information Systems Positivist Case Research: Current Practices, Trends and Recommendations," Management Information Systems Quarterly - MISQ , 27(4), pp. 597635.

Emrich, A., Ganz, F., Werth, D., and Loos, P. (2010). Enabling CrossApplication Traceability of Semi-
Structured Business Processes. Proceedings of the 1st International Workshop on Traceability and Compliance. Hoboken.

Erol, S., Granitzer, M., Happ, S., Jantunen, S., Jennings, B., Johannesson, P., Koschmider, A. (2010). "Combining BPM and Social Software:

Contradiction or Chance?," Journal of Software Maintenance and Evolution: Research and Practice.

Granovetter, M. (1973). The Strength of Weak Ties. The American Journal of Sociology, 78, pp.1360-1380.

Granovetter, M. (1983). The strength of weak ties: A network theory revisited. Sociological Theory, 1, pp.201-233.

Hevner, A. R., March, S. T., Park, J., and Ram, S. (2004). "Design Science in Information Systems Research," MIS Quarterly, 28(1), pp.75-105.

Houy, C., Fettke, P., \& Loos, P. (2010). Einsatzpotentiale von Enterprise-2.0Anwendungen - Darstellung des Stateof-the-Art auf Basis eines Literaturreviews. IWi Heft, 192.

Kaplan, A. M., and Haenlein, M. (2010). Users of the world, unite! The challenges and opportunities of social media. Business Horizons, 53, pp.59-68.

Kaplan, Robert, S., and Norton, David, P. (1992). The Balanced Scorecard Measures that thrive performance. Harvard Business Review, 70(1), pp.71-79.

Kietzmann, J. H., Hermkens, K., McCarthy, I., and Silvestre, B. S. (2011). "Social media? Get serious! Understanding the functional building blocks of social media," Business Horizons, 54(3), pp.241-251.

Kollmann, T., \& Häsel, M. (2007). Web 2.0 Trends und Technologien im Kontext der Net Economy. Wiesbaden: Gabler.

Komus, A. (2006). Social Software als organisatorisches Phänomen Einsatzmöglichkeiten in Unternehmen. HMD - Praxis der Wirtschaftsinformatik, 252.

Komus, A., and Wauch, F. (2008). Wikimanagement - Was Unternehmen 
von Social Software und Web 2.0 lernen können. Munich: Oldenbourg.

Lai, L., and Turban, E. (2008). Groups Formation and operations in the Web 2.0 environment and social networks. Group Decision and Negotiation, 17(5).

Lattemann, C., Stieglitz, S., and Kupke, S. (2009). "Deutsche Unternehmen auf dem Weg zum Web 2.0?" HMD Praxis der Wirtschaftsinformatik, 267.

Malone, T., Weill, P., Lai, R., Urso, V., and Herman, G. (2007). "Do Some Business Models Perform Better Than Others?", MIT Sloan Research, 4615(6), pp.1-34.

March, S. T., \& Storey, V. C. (2008). "Design Science in the Information Systems Discipline: An Introduction to the Special Issue on Design Science Research," MIS quarterly, 32(4), pp.725-730.

McAfee, A. P. (2006). "Enterprise 2.0: The dawn of emergent collaboration," MIT Sloan Management Review, 47(3), pp.21-28.

Muller, H. (2011). On Top of the Cloud: How ClOs Leverage New Technologies to Drive Change and Build Value. Hoboken: Wiley.

O'Reilly, T. (2005). What is Web 2.0. Design Patterns and Business Models for the Next Generation of Software. O'Reilly Media.

Patten, K. P., \& Keane, L. B. (2010). Enterprise 2.0 Management and Social Issues. Americas Conference on Information Systems (AMCIS) Lima, pp.1-8.

Ras, E., Rech, J., \& Weber, S. (2009). Investigating the Suitability of Web $X . Y$ Features for Software Engineering - Towards an Empirical Survey. Software Engineering (Workshops), pp.285-296.

Scheer, A.-W., Kruppke, H., Jost, W., \& Kindermann, H. (2007). Agility by ARIS Business Process Management - Yearbook Business Process Excellence. Berlin: Springer.
Schmelzer, H. J., and Sesselmann, W. (2008). Geschäftsprozessmanagement in der Praxis. München: Carl Hanser.

Schmidt, R., and Nurcan, S. (2008). BPM and Social Software. In D. Ardagna, M. Mecella, \& J. Yang (Eds.), BPM 2008 International Workshops, Milano, pp. 649-658.

Vom Brocke, J., and Rosemann, M. (2010). Handbook on Business Process Management. Berlin: Springer.

Voss, J. (2007). Tagging, Folksonomy \& Co Renaissance of Manual Indexing? 10th International Symposium for Information Science (ISI). Cologne.

Wagner, K., and Klückmann, J. (2006). Prozessdesign als Grundlage von Compliance Management. In A.-W. Scheer (Ed.), Agilität durch ARIS Geschäftsprozessmanagement. Berlin: Springer.

Weber, S., and Rech, J. (2009). An Overview and Differentiation of the Evolutionary Steps of the Web X.Y Movement: The Web Before and Beyond 2.0. Handbook of Research on Web 2.0, 3.0 and X.0: Technologies, Business. Hershey: Information Science Reference.

Werth, D., Di Valentin, C., Burkhart, T., and Loos, P. (2012). Towards A Design Proposal For Social Media Driven Business Process Management. International Conference on Internet Technologies \& Society (IADIS).

Weske, M. (2007). Business Process Management: Concepts. Languages, Architectures. Berlin: Springer.

Wirtz, W., and Ullrich, S. (2008). "Geschäftsmodelle im Web 2.0 Erscheinungformen, Ausgestaltung und Erfolgsfaktoren," HMD - Praxis der Wirtschaftsinformatik, 261.

www.forrester.com (2008). www.forrester.com. Retrieved from www.forrester.com on June 6, 2013. www.forrester.com (2013). www.forrester.com. Retrieved from www.forrester.com on June 8, 2013. 


\section{About Authors}

Dr. Dirk Werth is Head of Project Group Business Integration Technologies at the German Research Center for Artificial Intelligence (DFKI). He helds leading positions in multiple industrial consulting projects and started his career as scientific staff member at Saarland University, where he is still holding lectures on Enterprise Systems.

Dr. Werth holds diplomas in Business Administration and in Computer Sciences as well as a PhD in economics. His PhD thesis got the Special Award for Business Process Management from the Federal Association of German Political and Business Economists. His research activities comprise business process management and smart business information systems. He wrote and edited several books and published scientific papers and articles in international journals and proceedings.
Christina Di Valentin is a researcher at the German Research Center for Artificial Intelligence in Saarbruecken, Germany. Her main research areas include recommender systems, semantic web and business process management. Currently, she is working on the research projects "KOMMIT - Dealing competently with Media Technologies within VET" as well as in the project "SCORE Collaborative Enrichment of Business Processes" within the funding program "Software Campus" of the German Federal Ministry of Education and Research (BMBF). 